\title{
RECONHECER-SE COMO BRASILEIRO AO CONHECER A HETEROGENEIDADE LINGUIISTICO-CULTURAL HISPANO-AMERICANA
}

\author{
TO RECOGNIZE OURSELVES WHILE RECOGNIZING LINGUISTIC AND \\ CULTURAL HETEROGENEITY IN HISPANIC AMERICA
}

\author{
LUCIELENA MENDONÇA DE LIMA*
}

\begin{abstract}
RESUMO: Este artigo tem o objetivo de discutir os conceitos relacionados com a Educação Intercultural aplicados ao processo de ensino/aprendizagem de Espanhol como Língua Estrangeira (E/LE) no ensino médio brasileiro. Discutem-se, ainda, as bases teórico-metodológicas do documento Orientações Curriculares para o Ensino Médio- Espanhol (MEC, 2006). Apresentam-se, também, algumas sugestões de temas que podem ser trabalhados na sala de aula de E/LE para fomentar o conhecimento da heterogeneidade linguístico-cultural hispano-americana com o objetivo de reconhecer-se como cidadão brasileiro.

Palavras-chave: ensino de espanhol; heterogeneidade; interculturalidade.
\end{abstract}

\begin{abstract}
This article aims at discussing the conceptions related to Intercultural Education which are applied to the learning-teaching process of Spanish as a Foreign Language (S/FL) in the Brazilian secondary school. The theoretical and methodological bases of the document Orientações Curriculares para o Ensino Médio- Espanhol (MEC, 2006) are also considered. Some suggestions concerning themes that can be studied in the classroom of $\mathrm{S} / \mathrm{FL}$ are presented too, and this sort of work intends to foster knowledge about the Hispanic-American linguistic and cultural heterogeneity with the aim of leading the learners to recognize themselves as Brazilian citizens.

Keywords: the teaching of Spanish; heterogeneity; interculturality.
\end{abstract}

\section{INTRODUÇÃO}

Atualmente, em contextos de ensino de línguas estrangeiras (LE) e formação de professores, os formadores têm se preocupado em discutir as relações culturais e as perspectivas interculturais no ensino/aprendizagem de LE (SERCU, 2001); refletir sobre as contribuições das competências sociocultural e intercultural aplicadas ao ensino de LE; fomentar o uso de ferramentas tecnológicas para a pesquisa dos conteúdos culturais e analisar como os documentos oficiais sugerem o ensino dos conteúdos culturais. Portanto, em primeiro lugar, gostaria de ressaltar de que lugares teóricos eu falo. Assim, como professora/formadora de professores de espanhol, acredito, como Paulo Freire, que "Ninguém educa ninguém" e como Zeichner, teorizador do paradigma crítico para a formação de professores, citado por Richards e Lockhart (1998, p.187) ${ }^{1}$ que

*UFG-Faculdade de Letras, Goiânia (GO), Brasil. 1lima@letras.ufg.br

${ }^{1}$ No original: "[...] aprender a enseñar es un proceso que tiene lugar durante toda la vida profesional del profesor, y por mucho que hagamos en nuestros programas de formación, y por muy bien que lo hagamos, lo único que podemos hacer es preparar a los profesores para que empiecen a enseñar. Por tanto, la tarea de los 
DE LIMA - Reconhecer-se como brasileiro ao conhecer a heterogeneidade...

[...] aprender a ensinar é um processo que acontece durante toda a vida profissional do professor, e por muito que façamos em nossos programas de formação, e por melhor que o façamos, a única coisa que podemos fazer é preparar os professores para que comecem a ensinar. Portanto, a tarefa dos formadores de professores é ajudar os futuros profissionais a ter a disposição e a capacidade para estudar sua própria prática e para ensinar cada vez melhor, isto é, ajudar o professor a responsabilizar-se pelo seu próprio desenvolvimento profissional.

Em segundo lugar, acredito também que não existe uma única metodologia/método eficaz, como Celani (2009, p. 42) quando afirma que

[...] [n]ão existe um método perfeito, até porque a eficácia depende do objetivo da pessoa ao aprender um idioma. A saída agora é entender por quê, para quê, como e o que ensinar - nessa exata ordem. A primeira resposta pode ser: porque a língua confere uma formação global ao indivíduo. Para quê? Até o $9^{\circ}$ ano, ainda não há uma certeza. Então, a formação deve ser básica para permitir direcionamentos específicos posteriores. O como vai depender dos objetivos. Só então é possível definir os conteúdos a ensinar.

Em terceiro lugar, parto de uma concepção de língua(gem)-cultura defendida por Díaz $(2005, \text { p. } 837)^{2}$ a partir de

[o]s vários âmbitos disciplinares: a linguística, a pragmática, a psicolinguística, a etnografia da comunicação, a sociolinguística, etc., que se ocuparam do estudo da língua, enriqueceram os pontos de vista ao apresentá-la como um instrumento de comunicação e de interação e como a marca de identidade mais enérgica para cada grupo e cada indivíduo, quem, por sua vez, é concebido como um ator social que constrói - através da língua - as percepções, as representações, os comportamentos, as relações das imagens e os objetos, as relações sociais, isto é, sua identidade sociocultural. Ditos fatores naquelas características comuns e compartilhadas pelos membros e os grupos de um contexto social dados e ao perdurar no tempo - configuram as orientações culturais, uma cultura cujos componentes condicionam a comunicação efetiva e o adequado entendimento entre os interlocutores.

Em quarto lugar, parto da preocupação pela educação intercultural, que, segundo Fleuri (2000, p.78), é

uma relação que se dá, não abstratamente, mas entre pessoas concretas. Entre sujeitos que decidem construir contextos e processos de aproximação, de conhecimento recíproco e de interação.

formadores de profesores es ayudar a los futuros profesionales a lograr la disposición y la capacidad para estudiar su propia labor y para enseñar cada vez mejor, es decir, ayudar al profesor a que se responsabilice de su propio desarrollo profesional."

2 [1]os distintos ámbitos disciplinares: la lingüística, la pragmática, la psicolingüística, la etnografía de la comunicación, la sociolingüística, etc., que se han ocupado del estudio de la lengua, han enriquecido los puntos de vista al dar cuenta de Ella como un instrumento de comunicación y de interacción y como la marca de identidad más enérgica para cada grupo y cada individuo, quien, a su vez, concebido como un actor social que construye - a través de la lengua - las percepciones, las representaciones, los comportamientos, las relaciones de las imágenes y los objetos, las relaciones sociales, es decir, su identidad sociocultural. Dichos factores en aquellos rasgos comunes y compartidos por los miembros y los grupos de un contexto social dado y al perdurar en el tiempo - configuran las orientaciones culturales, una cultura cuyos componentes condicionan la comunicación efectiva y el adecuado entendimiento entre los interlocutores. (Grifos do autor) 
Trab. Ling. Aplic., Campinas, 50(1), Jan./Jun. 2011

Relações estas que produzem mudanças em cada indivíduo, favorecendo a consciência de si e reforçando a própria identidade. Sobretudo, promovem mudanças estruturais nas relações entre grupos. Estereótipos e preconceitos - legitimadores de relações de sujeição ou de exclusão - são questionados, e até mesmo superados, na medida em que sujeitos diferentes se reconhecem a partir de seus contextos, de suas histórias e de suas opções. A perspectiva intercultural de educação, enfim, implica em mudanças profundas na prática educativa [...]

\section{A EDUCAÇÃO INTERCULTURAL: PROPOSTA TEÓRICA}

É o Outro que permite construir as identidades próprias (individual e social) ${ }^{3}$. (GAVIDIA, 1995, p. 211).

[...] a educação e a cultura devem ter como última finalidade para o século XXI um desenvolvimento centrado no ser humano. (NANZHAO, 2003, p. 258).

[...] contemplar a reflexão - séria e profunda - em todos os âmbitos, em especial sobre o "estrangeiro" e suas (inter)relações com o "nacional", de forma a tornar (mais) conscientes as noções de cidadania, de identidade, de plurilinguismo e de multiculturalismo, conceitos estes relacionados tanto à língua materna quanto à língua estrangeira. Para tanto, é necessário levar em conta não só a língua estrangeira, mas, também, a realidade local/regional onde se dá o seu ensino. (OCEM- Espanhol, MEC, 2006, p. 149)

Estes são alguns dos objetivos propostos pelas Orientações Curriculares para o Ensino Médio para o processo de ensino/aprendizagem da língua espanhola, doravante OCEM- Espanhol, (MEC, 2006). Estão baseados na Educação Intercultural, portanto, é preciso discutir a pluralidade cultural e reconhecer os significados dos termos binários de alteridade/identidade, segundo Gavidia (1995). O sentimento de pertença a um grupo social é determinado por certas redes de significação, geralmente reconhecidas como significantes demarcativos de uma semiologia dos grupos, que constituem seu campo simbólico. A partir delas se reconhece o que é próprio, isto é, o que está dentro e pertence ao grupo, e que origina a representação do "em si"; e por oposição ou ausência se reconhece, também, o que é externo ao grupo, o estranho e o alheio, que origina a representação do "fora de si", e que vai produzir os efeitos de solidariedade ou aversão. Esta classificação da humanidade entre o que é próprio, ou seja, o "em si”, e o alheio, o deles, o "fora de si” cai no erro de emitir juízos de valor na diferença, sendo então o alheio algo estranho, bárbaro, pagão etc., isto é, carregado de conotações negativas, demonstrando uma postura etnocêntrica.

A alteridade é reconhecida na e a partir da diferença, no entanto, como destaca Jullien (1998, p.117-118) "a alteridade não é o mesmo que a diferença: a diferença pode ser identificada pontualmente, a alteridade remete a uma modificação das condições do

${ }^{3}$ No original: "Es el Otro quien permite construir las identidades propias (individual y social)". (GAVIDIA, 1995, p. 211). São minhas as traduções ao longo do texto.

${ }^{4}$ No original "la alteridad no es lo mismo que la diferencia: la diferencia puede identificarse puntualmente, la alteridad remite a una modificación de las condiciones del conjunto (mutatis mutandis), mientras que la diferencia puede interpretarse desde un marco común". (JULLIEN, 1998, p. 117-118) 
DE LIMA - Reconhecer-se como brasileiro ao conhecer a heterogeneidade...

conjunto (mutatis mutandis), enquanto a diferença pode ser interpretada a partir de um marco comum".

O sentimento de pertença a um grupo culturalmente homogêneo permite que as manifestações comunicativas sejam estabelecidas com base em uma linguagem comum, com códigos preestabelecidos e reconhecidos, com convenções linguísticas e com pressupostos culturais que possibilitam um discurso intracultural, isto é, dirigido a sua própria comunidade (Identidade). Na hora de querer estabelecer novas relações com outras comunidades culturalmente distintas, deve-se criar mecanismos e códigos novos e explícitos, que facilitam a compreensão e comunicação com este grupo linguisticamente diferente, isto enriquece a linguagem e a cultura própria, pois rompe a barreira da intraculturalidade para acessar o intercultural (Alteridade). Definitivamente, é o diálogo entre as culturas o que amplia o horizonte de recepção. O reconhecimento e a construção da própria identidade é um "ato interlocutivo entre o próprio e o alheio, no qual participam muitos Outros" (GAVIDIA, 1995, p. 211)

Ao definir-se o Outro a partir de "si mesmo", o Outro seria um "espelho invertido de si mesmo" (GAVIDIA, 1995, p.210) e ressalta, ainda, esta antropóloga que

[é] o Outro quem permite construir as identidades próprias (individual e social), e por isso, este é o anverso de uma problemática, considerada hoje como um dos objetivos centrais da Antropologia: alteridade/identidade como um binômio da realidade humana que se complementam" (GAVIDIA, 1995, p.211)

Portanto, aceita-se ou nega-se o Outro como diferente. E negar o Outro significa dar a conhecer o que é mau para si mesmo, isto é, julgar a partir dos próprios parâmetros.

O Outro hispano-americano, e por antonomásia, o Outro ibero-americano, é um produto de mestiçagem, ou seja, do enriquecimento de uma diversidade étnica. Afinal de contas todos são um produto mestiço, ao pensar-se nas diversidades étnica, racial e religiosa que dão forma à "encruzilhada cultural", como a nomearam alguns críticos a sociedade latino-americana.

Considerando os aspectos identitários expostos anteriormente, justifica-se a preocupação atual pela educação intercultural, principalmente porque a interculturalidade é o objetivo proposto por alguns documentos oficiais. Para a UNESCO, esta constitui um dos pilares para a educação do século XXI. Segundo Delors (2003, p. 96),

a educação deve utilizar duas vias complementares. Em um primeiro nível, está o descobrimento progressivo do Outro. Em um segundo nível, e ao longo de toda a vida, a participação em projetos comuns, que parecem ser um método eficaz para evitar ou resolver conflitos latentes ${ }^{8}$.

${ }^{5}$ No original: "acto interlocutivo entre lo propio y lo ajeno, en el cual participan muchos Otros" (GAVIDIA, 1995, p. 211).

${ }^{6}$ No original: "espejo inverso de sí mismo" (GAVIDIA, 1995, p. 210)

${ }^{7}$ No origina:l "Es el Otro quien permite construir las identidades propias (individual y social), y por ello, éste es el anverso de una problemática, considerada hoy como uno de los objetivos centrales de la Antropología: alteridad/identidad como un binomio de la realidad humana que se complementan" (GAVIDIA, 1995, p. 211).

${ }^{8}$ No original: "la educación debe utilizar dos vías complementares. En un primer nivel, está el descubrimiento progresivo del Otro. En un segundo nivel, y a lo largo de toda la vida, la participación en proyectos comunes, que parecen ser un método eficaz para evitar o resolver conflictos latentes" (DELORS, 2003, p. 96). 
Nas OCEM-Espanhol, (MEC, 2006, p. 151), cita-se o conceito de competência pluri(inter)cultural presente no Quadro Europeu Comum de Referência (CONSELHO DA EUROPA, 2001, p. 25):

[a] língua não é somente um aspecto fundamental da cultura, mas é também um meio de aceso às manifestações culturais. [...] Na competência cultural de um indivíduo, as várias culturas (nacional, regional, social) às quais esse indivíduo teve acesso não co-existem simplesmente lado a lado. São comparadas, contrastam e interagem activamente para produzir uma competência pluricultural enriquecida e integrada, da qual a competência plurilingue é uma componente, que por sua vez interage com outras componentes ${ }^{9}$.

Ser mais tolerantes, relativizar os próprios pontos de vista e estar receptivos para o novo são vantagens dessa abordagem, que, além de propor a possibilidade de uma convivência pacífica, humaniza o processo da globalização e contribui para a diminuição do preconceito, sem mencionar a aprendizagem dos elementos culturais da língua estrangeira (LE) que esse diálogo gera. Em princípio, essa proposta de entender e dialogar sobre a diversidade cultural pode parecer uma tarefa muito difícil, porém quando se propõe o uso da sala de aula de LE para essa discussão, o cumprimento desse objetivo parece bastante factível, pois quem se dispõe a aprender uma língua geralmente está aberto a conviver com as culturas veiculadas por ela.

Portanto a adoção de uma abordagem intercultural na sala de aula supõe que os alunos e professores participem como agentes sociais. No entanto, não é preciso renunciar aos próprios recursos culturais e imitar os comportamentos dos nativos da língua-alvo, posto que, como brasileiros, já são socializados nas culturas da língua materna (LM). Neste sentido, aprender uma LE significa aprender a ter um novo status social: como representante das culturas maternas; como novo integrante de comunidades cujos rituais e convenções é necessário aprender e aprender a respeitar, e como intermediador cultural das comunidades com as quais se entra em contato.

Desse modo, é necessário considerar a realidade local/regional deste imenso Brasil e das 21 nações que falam oficialmente a língua espanhola. Segundo as OCEM-Espanhol (MEC, 2006, p. 149), significa explicitar

[o] enfrentamento da diversidade certamente [que] comportará representações - sobre o próprio e sobre o alheio, valendo-nos de termos empregados por Fanjul (2000) - que se manifestam no discurso em forma de "estereótipos, idealizações, exotismos, etc.", como aponta Serrani-Infante (1998: 265), representações que deverão ser analisadas, segundo a autora (ibid.), “[...] como meios imaginários nos quais se imbricam as questões simbólicas [...] e ideológicas [...]." Tais representações, algumas muito alimentadas pela mídia, ora se projetam sobre a própria língua e suas variedades, ora sobre os seus muitos e distintos falantes, situados, sobretudo, em distintas regiões, mais ou menos favorecidas e prestigiadas, ora se projetam sobre a facilidade ou dificuldade de enfrentar o processo de aprendizagem. Todas elas, a nosso ver, precisam ser objeto de algum tipo de trabalho analítico-crítico, quer seja para serem, em alguns casos, exploradas e em outros, abaladas.

\footnotetext{
${ }^{9}$ Citamos a tradução oficial deste documento ao português de Portugual, sem fazer alterações.
} 


\section{IMPLICAÇÕES DIDÁTICO-METODOLÓGICAS}

Desse modo, os professores precisam responder a perguntas tais como: que práticas educativas nas aulas de espanhol ajudam a formar os alunos como cidadãos críticos? Qual é o papel do ensino/aprendizagem do espanhol na educação básica brasileira? Essas perguntas levam a respostas que passam pela discussão da própria identidade linguísticocultural brasileira e pelo reconhecimento da heterogeneidade linguístico-cultural hispanoamericana, para que os alunos possam se identificar com algumas das culturas dos países que compõem o mundo hispânico.

Para Casal (1999, p.14),

[o] processo de ensino/aprendizagem de línguas estrangeiras não pode limitar-se, portanto, a ser uma mera versão de habilidades e conhecimentos linguísticos, mais ou menos sofisticados; faz-se necessário supor, de alguma forma, a transmissão de atitudes e valores da cultura alvo. É necessário tentar, pois, levar à sala de aula os modos de ver a realidade, de entendê-la e de interpretá-la dos falantes nativos. ${ }^{10}$

Portanto, é preciso reconhecer que o processo de aprendizagem de línguas vai muito além do aspecto cognitivo, posto que, segundo Serrani-Infante (1998, p.249), este processo deve ser entendido como a "[...] inscrição do sujeito pelo processo de tomada da palavra em discursividades de uma dada L2", o que equivale dizer que se o aprendiz não se identifica com o que está aprendendo muito pouco lhe restará. Esta mesma autora explica: "vejo a identificação como a condição instauradora, a um só tempo, de um elo social e de um elo com o objeto do desejo do sujeito". Isto quer dizer que, sem o processo identificatório "não é possível uma tomada da palavra significante na L2" (SERRANIINFANTE, 1998, p. 252-253). O que significa dizer que, ainda que se consiga aprender o código linguístico, pode ser que as práticas comunicativas não sejam significativas por não existir a identificação do ponto de vista subjetivo.

No $3^{\circ}$ capítulo sobre os Conhecimentos de línguas Estrangeiras (MEC, 2006, p.111112) também se sugere o trabalho com os temas, ao afirmar que

[...] o planejamento de curso para as aulas de línguas estrangeiras tenha, como ponto de partida, temas. O desenvolvimento das habilidades deve, então, ser pensado a partir deles. Sugestões de temas: cidadania, diversidade, igualdade, justiça social, dependência/interdependência, conflitos, valores, diferenças regionais/nacionais. No entanto, naquelas regiões do país onde há possibilidades de contextos locais de uso do idioma estrangeiro, pode-se partir de contextos para o ensino de Línguas Estrangeiras. Nas outras regiões, podem ser privilegiados os temas mais do que o contexto de uso.

Acerca dos objetivos e conteúdos a ser considerados no processo de ensino/ aprendizagem de espanhol, perseguindo o objetivo da formação do cidadão, este mesmo

\footnotetext{
${ }^{10}$ No original: "el proceso de enseñanza/aprendizaje de lenguas extranjeras no puede limitarse, por tanto, a ser un mero trasvase de habilidades y conocimientos lingüísticos, más o menos sofisticados; ha de suponer, en alguna medida, la transmisión de actitudes y valores de la cultura meta. Habrá que intentar, pues, llevar al aula los modos de ver la realidad, de entenderla y de interpretarla que poseen los hablantes nativos. (CASAL, 1999, p. 14).
} 
documento no $4^{\circ}$ capítulo, sugere que “[...] [n] esse sentido, pensando sobretudo na ideia de transversalidade, tão presente na lei que rege a educação brasileira - podem-se incluir reflexões sobre: políticas, econômicas, educação, sociais, esportes, lazer, informação, línguas e linguagens“. (MEC, 2006, p. 149-150). A lista poderia ser ampliada, incluindo a cultura clássica, história, geografia, artes, pontos turísticos etc. No entanto, os temas que podem provocar dificuldades de interpretação e/ou mal entendidos, certamente, são os relacionados com a cultura popular, política atual, gastronomia, religiosidade, festas religiosas e populares, crenças, tradições, literatura popular, artes, relações sociais e familiares, lazer, línguas cooficiais, variedades linguísticas. Estas podem ser classificadas como:

(I) diafásicas ou estilos de língua (resultado dos usos devido às diferentes atitudes que os interlocutores querem mostrar, segundo as circunstâncias características do modo de falar, ou do processo de produção: relação simétrica ou assimétrica entre os interlocutores, situação comunicativa, o assunto do qual se fala, entre outros);

(II) diastráticas ou socioletos (resultado do uso da língua por diferentes níveis socioculturais: culto, coloquial, vulgar, popular; e

(III) diatópicas ou geográficas (atendendo à diversidade determinada pelo estabelecimento da língua no espaço geográfico. Segundo Ureña $\left(1976\right.$, p.5) ${ }^{11}$, “[...] provisoriamente me arrisco a distinguir na América espanhola cinco zonas principais". Estas, nomeadas por Fernández (2000), são mexicana e centro-americana, caribenha, andina, chilena e rio-platense. Complementado esta classificação das zonas dialetais hispânicas, este autor acrescenta três peninsulares: castelhana, andaluza, canária.

Portanto, “[...] nesse sentido, o papel de professores passa a ser quase o de articuladores de muitas vozes", segundo as OCEM-Espanhol, (MEC, 2006, p. 136), possibilitando a realização de uma reflexão que leve a superar o discurso hegemônico que divulga a crença do mito do falante nativo, que, no caso da língua espanhola, é o espanhol da Espanha ou, mais especificamente, o castelhano.

Com relação a este mito, as OCEM-Espanhol, (MEC, 2006, p. 134) citam as pesquisas realizadas por Santos $(2002,2004,2005)$ que

[...] aponta a existência de uma forte tendência, por parte dos brasileiros, a classificarem o Espanhol peninsular como "puro, original, clássico, rico, perfeito, mais correto", enquanto a variedade rioplatense, por exemplo, é vista como "derivada", "diferente", "carregada de particularidades", "com mistura de outras línguas", "com gírias e manias locais", "mais popular". (Grifos do autor)

Portanto, apoiamos e adotamos o discurso da heterogeneidade linguística e reconhecemos a existência da diversidade das demais sete zonas dialetais, já que, ao passar a reconhecer-se como latino-americanos que todos os brasileiros são, não se pode mais aceitar os estereótipos do espanhol americano, pois "é preciso que a escola atue no sentido de evitar dicotomias simplificadoras e reducionistas e que permita a exposição dos estudantes à variedade sem estimular a reprodução de preconceitos", como defende as OCEM- Espanhol (MEC, 2006, p. 134), já que, subjetivamente, pode haver identificação

${ }^{11}$ No original "[...] provisionalmente me arriesgo a distinguir en la América española cinco zonas principales". 
DE LIMA - Reconhecer-se como brasileiro ao conhecer a heterogeneidade...

com qualquer uma das variedades e variantes linguísticas, durante o processo de ensino/ aprendizagem de E/LE.

Como técnicas didáticas, pode-se usar a aproximação e o contraste das próprias culturas da LM com as da língua-alvo (espanhol), pois são exercícios imprescindíveis para desenvolver uma opinião crítica, já que, não aceitar ou não compreender as culturas do outro são marcas de preconceitos que devem ser relativizados, eliminados e substituídos pelo diálogo intercultural.

Como atividades didáticas, pode-se propor aos alunos a elaboração e a realização de tarefas comunicativas e projetos de pesquisa que sigam as características da aprendizagem cooperativa, porque são necessários a contribuição, os esforços e os conhecimentos de todos os componentes do grupo. Como afirma Crandall (2000, p. 243), este tipo de atividade:

[...] requer interação social e negociação de significados entre membros de grupos heterogêneos envolvidos em tarefas em cuja realização todos os componentes do grupo têm algo com o que contribuir e algo a aprender com os outros membros. A aprendizagem cooperativa supõe mais do que uma simples atividade de grupo reduzido. Em uma tarefa cooperativa bem estruturada há um autêntico vazio de informação [...]. ${ }^{12}$

\section{CONSIDERAÇÕES FINAIS}

À guisa de conclusão, o objetivo de fomentar a educação intercultural no ensino de LE exige uma mudança nos papéis que tradicionalmente são atribuídos ao professor e ao aluno. Por isso, antes de estimular a consciência intercultural dos aprendizes, é imprescindível que o professor tenha passado por um processo de reflexão crítica e que, como consequência, tenha vivenciado mudanças em seu autoconceito, em suas qualificações profissionais, atitudes e habilidades docentes.

\section{REFERÊNCIAS BIBLIOGRÁFICAS}

CASAL, I.I. (1999). Comunicación intercultural y enseñanza de lenguas extranjeras: hacia la superación del etnocentrismo. In: Boletín de ASELE. Málaga: ASELE, p. 13-23.

CELANI, A. (2009). Nova Escola. São Paulo: Abril, p. 142.

CONSELHO DA EUROPA. (2001). Quadro europeu comum de referência para as línguas: aprendizagem, ensino, avaliação. Porto: Edições ASA.

CRANDALL, J. (2000). El aprendizaje cooperativo de idiomas y los factores afectivos. In: ARNOLD, J. (org.) La dimensión afectiva en el aprendizaje de idiomas. Trad. Alejandro Valero. Cambridge: Cambridge University Press, p. 243-261.

${ }^{12}$ No original: “[...] requiere interacción social y negociación de significados entre miembros de grupos heterogéneos implicados en tareas en cuya realización todos los componentes del grupo tienen algo que contribuir y algo que aprender de los otros miembros. El aprendizaje cooperativo supone más que una simple actividad de grupo reducido. En una tarea cooperativa bien estructurada hay un auténtico vacío de información [...]" (CRANDALL, 2000, p. 243). 
Trab. Ling. Aplic., Campinas, 50(1), Jan./Jun. 2011

DELORS, J. (2003). Educação: um tesouro a descobrir. 8 ed. São Paulo: Cortez; Brasília, DF: MEC: UNESCO.

DÍAZ, C. G. (2005). Los contenidos culturales. In: LOBATO, J. S.; GARGALLO, I. S. (org.) Vademécum para la formación profesores. Enseñar español. Madrid: SGEL, p. 835-852.

FERNÁNEZ, F. M. (2000). ¿Que español enseñar? Madrid: Arco Libros.

FLEURI, R. M. (2000). (org.) Educação intercultural. Mediações necessárias. Rio de Janeiro: DP\&A.

GAVIDIA, N. G. (1995). Los indígenas venezolanos: de su demonización en la "Historia de la nueva Andalucía (1779) a la persecución actual por la ideología del progreso. Visión de los otros y visión de sí mismo. Biblioteca de Historia de América. Madrid: Consejo Superior de investigación Científicas, p. 205-234;

JULLIEN, F. (1998). El mayor rodeo: la sinología como disciplina occidental. In: TODOROV, T. (org.) El cruce de culturas y mestizaje cultural. Madrid: Júncar Univ., p. 117-118.

KRAMSCH, C. (1999). El privilegio del hablante intercultural. In: BYRAN, M.; FLEMING, M. (org.) Perspectivas interculturales en el aprendizaje de idiomas. Enfoques a través del teatro y etnografia. Cambridge: Cambridge University Press, p. 23-37.

MINISTÉRIO DA EDUCAÇÃO. (2006). Secretaria de Educação Básica. Orientações Curriculares Nacionais do Ensino Médio: Línguas Estrangeiras / Espanhol. V. 1 Cap. 3. Conhecimentos de língua estrangeira. Brasília: MEC, p.87-124.

(2006). Secretaria de Educação Básica. Orientações Curriculares Nacionais do Ensino Médio: Linguas Estrangeiras / Espanhol. V. 1 Cap. 4. Conhecimentos de Espanhol. Brasília: MEC, p.125164.

NANZHAO, Z. (2003). Interações entre educação e cultura, na óptica do desenvolvimento econômico e humano: uma perspectiva asiática. In: DELORS, J. (org.) Educação: um tesouro a descobrir. 8 ed. São Paulo: Cortez; Brasília, DF: MEC: UNESCO, p. 257 - 267.

RICHARDS, J. C.; LOCKHART, C. (1998). Estrategias de reflexión sobre la enseñanza de idiomas. Trad. Juan Jesús Zaro. Cambridge: Cambridge University Press .

SERCU, L. (2001). Formación de profesores en ejercicio y adquisición de competencia intercultural. In: BYRAM, M.; FLEMING, M. (org.) Perspectivas interculturales en el aprendizaje de idiomas: enfoques a través del teatro y de la etnografía. Madrid: Cambridge University Press, p. 254-286.

SERRANI-INFANTE, S. M. (1998). Identidade e segundas línguas: as identificações no discurso. In: SIGNORINI, I. (org.) Língua(gem) e identidade. Campinas: Mercado de Letras/São Paulo: Fapesp, p. 231-264.

UREÑA, P. E. (1976). Observaciones sobre el español en América y otros estudios filológicos. Buenos Aires: Academia Argentina de Letras.

Recebido: 28/04/2010

Aceito: 11/04/2011 
